assigned to them by the late Prof. Sahni, as previously known records of this genus are either from Tertiary or the post-Tertiary periods. It is also interesting to note that this fossil species is closely related to, but certainly not identical with, Salvinia auriculata, a species spread from Cuba to Brazil in South America. This reminds one of the fact that the living representatives of two other important fossil plants from the Deccan Intertrappean cherts, namely, Cyclanthodendron ", related to modern Cyclan. thaceæ growing in shallow waters and estuaries in Brazil, and Rodeites, a fossil representative of the monotypic genus Regnellidium ${ }^{7}$ belonging to the Marsiliaceæ, are also from Brazil, South America. Apparently, the resemblance between the Early Tertiary flora of the Deccan and the modern flora of tropical South America is more than striking.

T. S. Mahabalí

Department of Botany,

Royal Institute of Science,

Bombay 1, India. Sept. 20.

${ }^{1}$ Sahni, B., and Shrivastava, B. P., Proc. 21 st Ind. Sci. Congr., 318 (1934).

Sahni, B., and Rao, H. S., Proc. Nat. Acad. Sci., India, 13, 56 (1943)

'Sahni, B,, and Rao, H. S., Proc. Nat. Acad. Sci., India, 13, 58 (1943).

- Sahni, B., Proc. 27th Ind. Sci. Congr., General Presidential Address, $14(1940)$

5 Sahni, B., and Rao, H. S., loc. cit., 56 and Figs. 56-63.

- Sahni, B, and Surange, K. R. Nature, 154, 114 (1944).

- Sahni, B., J. Ind. Bot. Soc., 22, 180, pl. 9, flg. 42 (1943).

\section{Alkaloid Tests on Herbarium Specimens}

A systematic survey of Australian plants for alkaloids, begun in 1944 by the Division of Plant Industry, Commonwealth Scientific and Industrial Research Organisation, has already involved the testing of several thousand species for alkaloids and other compounds of possible chemical or pharmacological interest. Most of these tests were done in the field on fresh samples of bark, leaves, roots, wood or fruits.

For alkaloids, a simple and rapid semi-micro test, requiring about $0.1 \mathrm{gm}$. dried plant material, was devised, using conventional reagents. The precipitates were evaluated qualitatively on $a+$ to ++++ basis, that is, traces to substantial amounts of alkaloidal substances.

The small amount of material required for these tests suggested the possibility of their application to fragments of herbarium specimens, particularly since it has proved impracticable to locate all members of promising groups in the field. Fragments from specimens in the Queensland Herbarium were kindly made available by the Government Botanist (Mr. C. T. White). These tests, which are obviously applicable only to alkaloids and alkaloidal substances which occur in leaves or branchlets, and which are stable under the conditions of preservation of herbarium specimens, have made possible a rapid screening of promising groups.

Thus, in Rutaceæ, which contains 26 genera and 117 species in Queensland, 13 genera and 32 species have been found to give good positive tests. Laboratory extractions have confirmed the presence of alkaloids in 13 of the 32 species which gave positive tests; another four have not yielded alkaloids, and the remaining fifteen species have not yet been examined in detail. In those cases (66 spp.) where tests on fresh material have also been made, the results were in good agreement with those on herbarium specimens. Where aberrations were encountered, herbarium specimens collected over the past few years usually gave better alkaloidal tests than those collected ten to fifty years ago. In other cases, however, the consistency of the results with specimens of varying age indicated the presence of very stable alkaloids. The most remarkable was Acronychia baueri, of which a sample collected by Alan Cunningham in 1824 gave atrongly positive tests.

It is suggested, with the reservations noted above, that a reconnaissance of world alkaloid resources could be made by similarly examining specimens from various central herbaria.

Herbarium specimens are now being used to provide a complete investigation of all promising alka. loidal groups in the Queensland flora, including groups not yet encountered in the field. The results of these and other field tests, together with details of methods, will be published elsewhere.

Plants and Soils Laboratory,

L. J. WEBB

Commonwealth Scientific and

Industrial Research Organisation, Brisbane.

Nov. 7.

\section{Indigenous Tilia platyphyllos in Britain}

In Late-Quaternary deposits in England, pollen grains of Tilia have their maximum frequency, as a rule, in strata formed during the Post-Glacial climatic optimum. This fact was reported many years ago ${ }^{1}$, and has been amply confirmed by later investigations. To the finds of Tilia pollen made hitherto (exclusively finds of $T$. cordata ${ }^{2}$ ) can now be added the finding by one of us (J.P.T. B.) of peat at Addington, Kent, the pollen flora of which was later investigated by Erdtman and found to contain-in its basal portions--pollen grains of Tilia platyphyllos. This peat bed seals an occupation site of Mesolithic age characterized by axes, gravers and microliths.

The peat samples contained pollen grains of alder, birch and hazel. There occurred, in addition, pollen grains of oak, lime (frequency about 10 per cent) and elm, together with a few stray pollen grains of holly, ivy and Scleranthus perennis. Spores of Polypodium vulgare were also present. There were no pollen grains of pine, beech and hornbeam, etc.

The above evidence favours the assumption-to be corroborated or modified by further detailed investigations-that the basal portion of the peat was formed in Neolithic times.

Several hundred lime pollen grains were investigated under high-power magnification, and it was found that about 5 per cent of them came from $T$. platyphyllos, whereas 75 per cent came from $T$. cordata and the hybrid between $T$. platyphyllos and $T$. cordata. The remaining 20 per cent of the grains could not be determined on account of partial sporoderm destruction.

J. P. T. BurchelL

Falcon Cottage,

G. ERDTMAN

Fawke Common,

Sevenoaks, Kent. Dec. 14.

${ }^{1}$ Naturalist, 252 (1926); J. Bot., 73 (1926).

${ }^{2}$ New Phytol., 389 (1940). 